\title{
Internet addiction and its correlation with behavioral problems and functional impairments - A cross-sectional study
}

\author{
Dependência de internet e sua correlação com sintomas \\ comportamentais e prejuízos funcionais - Um estudo transversal \\ Mayara de Rezende Machado', Isac Bruck², Sérgio Antonio Antoniuk², Mônica Nunes Lima Cat³, \\ Maurício César Soares ${ }^{4}$, Alcir Francisco da Silva ${ }^{1}$
}

\section{Keywords}

Internet, attitude to computers, adolescents, behavioral symptoms, child behavior.

\section{Palavras-chave}

Dependência de internet, uso patológico de internet, adolescentes, sintomas comportamentais, Internet Addiction Test, Child Behavior Checklist.

Received in
$31 / 5 / 2017$
Approved in
$26 / 11 / 2017$

\section{RESUMO}

Objetivo: Avaliar a prevalência da dependência de internet entre adolescentes, assim como caracterizar comportamentos de risco nessa população em relação ao uso e à dependência de internet. Métodos: Estudo transversal analítico realizado em dois colégios, um público e um particular, com 91 adolescentes de idade entre 12 e 16 anos, que responderam aos questionários Internet Addiction Test - versão brasileira (IAT) e Child Behavior Checklist (CBCL). Resultados: Entre a população estudada, a prevalência de dependência de internet encontrada foi de 21\%, não havendo diferença entre as escolas pública e particular. No grupo dependente de internet, houve relação estatisticamente significativa com os sintomas Ansiedade/Depressão, Isolamento/Depressão e Comportamento Agressivo e de Quebrar Regras. As escalas Problemas Sociais, Problemas de Pensamento e Problemas de Atenção também se correlacionam à dependência de internet. Conclusão: $O$ presente estudo demonstra evidência de correlação entre a dependência de internet e sintomas comportamentais entre adolescentes. Por se tratar de um estudo transversal, contudo, esses dados devem ser vistos com cautela e pesquisas futuras são necessárias para corroborar nossos resultados.

1 Universidade Federal do Paraná (UFPR), Hospital de Clínicas, Pediatric Neurology Program.

2 Universidade Federal do Paraná (UFPR), Pediatrics Department of the Pediatric Neurology Center (CENEP).

3 Universidade Federal do Paraná (UFPR), Scientific Research and Health Statistics Methodology Unit of the Pediatrics Department, Pediatrics Department.

4 Fundação de Assistência ao Estudante (FAE), Centro Universitário.

Linked Institution: Hospital de Clínicas - Universidade Federal do Paraná

Address to correspondence: Mayara de Rezende Machado

Av. Manoel Ribas, 2045, Mercês

80810-000 - Curitiba, PR, Brasil

E-mail: mayaramachado@gmail.com 


\section{INTRODUCTION}

Internet access has become increasingly popular in Brazil, and recent IBGE (Brazilian Institute of Geography and Statistics) data has indicated a growth of 143.8\% between 2005 and 2011 in the number of people aged 10 or more who use the internet. It should be emphasized that young people represent most of these users with the highest percentages corresponding to groups of 10 to 14 years old ( $63.3 \%$ of this age group) and 15 to 17 years old (74.1\%)'. According to a recent survey regarding the use of internet by children and adolescents in Brazil, there was a significant increase in the frequency of internet use and mobile devices such as mobile phones and tablets, which reduces the mediation of parents, teachers and legal guardians ${ }^{2}$.

Children and adolescents appear to be particularly attracted by virtual networks in which it's possible to create a new coexistence space with proper communication characteristics, where anonymity and autonomy are intrinsic properties. In addition, they have time available and easy access $^{3-6}$. During adolescence, a period full of insecurities, online communication is often chosen over face-to-face interaction. People from this generation, also known as the digital generation, have been continuously and constantly exposed to the Internet since childhood, and may have difficulty distinguishing between the real and the virtual world, which can often result in excessive exposure to social media?.

Therefore, with the use of internet gradually more widespread, the concern about its excessive use and addiction has been raised, as well as possible associated neurobehavioral symptoms ${ }^{8}$. However, the definition of "internet addiction" is still controversial, but is based on the understanding that its frequent and excessive use has negative consequences for people's lives, either in the social or academic environment, resulting in psychological distress and functional impairment ${ }^{9,10}$.

Several hypotheses have been raised to explain this phenomenon, for example, that the use of the Internet is an "escape valve" for these adolescents" ${ }^{11}$. Another hypothesis describes internet addiction as having neurophysiological mechanisms similar to chemical dependencies and impulsivity ${ }^{12,13}$. Furthermore, there seems to be no exact conclusion whether internet addiction encourages the occurrence of other psychiatric symptoms or, on the other hand, people with psychiatric disorders are more likely to become addicted to the internet ${ }^{14}$.

With the intensification of studies related to internet addiction in recent years, a number of measuring methods have been created in the search for a tool that could identify individuals at risk. The Internet Addiction Test (IAT) is the most used tool in this sense, created in the 1990s and since then has been adapted to different languages and different cultures, including Portuguese (Teste de Dependência de
Internet). It is a reliable measure capable of classifying people as to their internet use as normal, mild, moderate and severe, based on 20 Likert scale questions ${ }^{15,16}$.

According to international studies, the prevalence of pathological internet use varies from zero to $26.3 \%$ among young Americans ${ }^{17}$ and $4.2 \%$ in Europe ${ }^{18}$. In China, the percentage of moderate internet users is $10.6 \%$ and for those considered addicts is $0.6 \%{ }^{19}$. In Latin America, the data is scarce, and only one study from Colombia brings a 12\% prevalence of problematic internet use among Colombian university students ${ }^{20}$. In Brazil, a study to evaluate this dimension has not yet been done, which justifies our research.

The literature has shown an association between excessive internet use and behavioral symptoms among children and adolescents, from hostility and aggression to social withdrawal and depressive symptoms ${ }^{21-24}$. A multicentric study conducted in 11 European countries identified an association between Internet addiction and depression, anxiety symptoms, behavioral problems and hyperactivity/attention deficit disorder, as well as suicidal ideation and suicide attempts ${ }^{18}$. There is no data regarding the association of internet addiction and behavioral symptoms in the Brazilian pediatric population.

Considering the scarcity of research on the subject in our population, the study aim is to evaluate the prevalence of internet addiction among adolescents through the IAT, and identify possible behavioral symptoms and functional impairments among this internet-dependent population using the Child Behavior Checklist (CBCL).

\section{METHODS}

A cross-sectional study conducted in two schools in Curitiba/ PR - one public school (Escola Municipal Julia Amaral Di Lena) and one private school (Colégio Sagrado Coração de Jesus) after approval by the Ethics Committee of the Hospital de Clínicas/UFPR (CAAE Number: 44183515.3.0000.0096).

Every participating school received 250 envelopes containing the IAT, the $\mathrm{CBCL}^{25}$, the Informed Consent Form (ICF) and the Informed Agreement Form (IAF). The researchers visited the schools and explained in all participating classes the study objectives and the appropriate way to fill out the questionnaires. The inclusion criteria was children and adolescent aged between 12 and 16 years old, and the ICF, the IAF, the IAT and the CBCL correctly filled in. The exclusion criteria was the incorrect completion of the questionnaires, whether by the adolescents or the parents, due to illiteracy or illegibility.

For the statistical analysis, the Student T Test, the Fisher Two-Tailed Test and Pearson Correlation were used. In all statistical tests, $p<0.05$ was considered statistically significant. 
Symptoms related to internet addiction were evaluated from the results of the IAT, filled in by the adolescent. Those who obtained scores equal to or higher than 50 points were considered Internet addicts, which is the cut-off point for moderate internet addiction ${ }^{15}$.

For the screening of behavioral symptoms and functional impairments, the results of the $\mathrm{CBCL}$, an instrument considered a golden standard for this purpose, completed by parents ${ }^{25-27}$, were used. These questionnaires were processed into individual scores divided into Internalizing symptoms (anxiety/depression, withdrawn/depression and somatic complaints), Externalizing symptoms (rule-breaking and aggressive behavior), Total Behavior Problems, Total Social Competence (this section assesses the participant's activities, relationships and school performance) and DSMoriented Scales, that are based upon critical items of the CBCL considered to be consistent with Diagnostic and Statistical Manual of Mental Disorders (DSM-IV) diagnostic categories. Such individual scores are converted into T-scores according to gender and age, indicating whether the person has any deviant behavior or poor social competence in relation to age and gender, the latter including social relationships, extracurricular activities and academic performance. This characterization is given as "clinical", "borderline" and "nonclinical". The "clinical" category indicates low scores for social competence and high for emotional and behavioral issues; "borderline" represents an intermediate range that requires the need for long-term monitoring; and the "non-clinical" category would be the opposite of the "clinical" category. In this study, adolescents who met the "borderline" criteria were categorized as "clinical", since the classification of "borderline" indicates that this individual should at least have a follow-up.

\section{RESULTS}

The total number of returned questionnaires was 151 . However, by applying the inclusion and exclusion criteria, the final total sample consisted of 91 participants (18.2\% of the total provided questionnaires), with 44 participants from private school and 47 from public school, with no statistically significant difference. The average age was 12.8 years old, with statistically significant differences between schools (12.4 years old for public school and 13.2 years old for private school, SD 1,29 and p-value 0,001), but clinically insignificant for the objective of our study. Among the 91 participants, 66\% were female and 34\% were male. There was no statistical difference regarding gender in relation to public and private schools.

The prevalence of internet addiction, considering an IAT score equal to or higher than 50 points, was $21 \%$. In public schools, 10 participants met the criteria for internet addiction (21.3\%), and, in the private school, 9 participants (20.4\%) met the same criteria. Therefore, there was no difference in the number of Internet Addicts participants in relation to public and private schools.

Comparing the $\mathrm{CBCL}$ results between public and private schools, it was observed that participants who attend public school were more impaired regarding Total Social Competence compared to the private school $(p<0.01354)$, meaning that the public school participants seems to have less extracurricular activities, poorer social interactions and more problems at school. In addition, the Aggressive and Rule-Breaking behavior seems to be more frequent within the public school group, however, the $\mathrm{n}$ for these groups was very small, making it difficult to statistically analyze these cases (Table 1).

Table 1. Comparisons between Total Social Competence and Behavioral Symptoms versus public and private schools

\begin{tabular}{lccc}
\hline & $\begin{array}{c}\text { Public } \\
\text { School ( } \mathrm{n}=47)\end{array}$ & $\begin{array}{c}\text { Private } \\
\text { School }(\mathrm{n}=44)\end{array}$ & $\mathbf{p}$ \\
\hline Aggressive behavior & 10 & 5 & $>0.05$ \\
Rule-breaking behavior & 7 & 2 & $>0.05$ \\
Attention problems & 9 & 5 & $>0.05$ \\
Thought problems & 7 & 7 & $>0.05$ \\
Social problems & 12 & 5 & $>0.05$ \\
Somatic complaints & 11 & 9 & $>0.05$ \\
Withdrawn/depression & 11 & 8 & $>0.05$ \\
Anxiety/depression & 8 & 5 & $>0.05$ \\
Total social competence & 30 & 17 & $<0.05$ \\
\hline
\end{tabular}

When comparing individuals considered Internet Addicts and non-Internet Addicts with the results obtained in Total Social Competence from the CBCL, $94.12 \%$ of the group considered addicts with impairment in Total Social Competence. On the other hand, among the non-Addicts group, $47.7 \%$ had impairment in this regard. The p-value in this case is $<0.0006$, so there is a statistically significant correlation between internet addiction and impairment regarding Total Social Competence.

In relation to behavioral symptoms, a statistically significant relationship was observed between the Internet Addicts group and Aggressive and Rule-Breaking behavior, Attention Problems, Thought problems, Social Problems, Withdrawn/Depression, and Anxiety/Depression, in comparison to the non-Internet Addicts group. Only the item Somatic Complaints did not reveal the same statistical significance (Table 2). Likewise, Internalizing Symptoms, Externalizing Symptoms and Total Problems are correlated with internet addiction (Table 2). 
Table 2. Comparisons between the Internet Addiction group and the non-addicted group versus Behavioral Symptoms, Externalizing and Internalizing Problems and the Total Problems Scores $(C B C L)$

\begin{tabular}{lccc}
\hline & IAT $<50(\%)$ & IAT $\geq 50(\%)$ & $\mathbf{p}$ \\
\hline Aggressive behavior & 11.11 & 36.84 & $<0.05$ \\
Rule-breaking behavior & 4.17 & 31.58 & $<0.05$ \\
Attention problems & 9.72 & 36.84 & $<0.05$ \\
Thought problems & 6.94 & 47.37 & $<0.001$ \\
Social problems & 12.50 & 42.11 & $<0.05$ \\
Somatic complaints & 18.06 & 36.84 & $>0.05$ \\
Withdrawn/depression & 15.30 & 42.11 & $<0.05$ \\
Anxiety/depression & 8.33 & 36.84 & $<0.05$ \\
Externalizing problems & 19.44 & 63.16 & $<0.001$ \\
Internalizing problems & 26.39 & 68.42 & $<0.05$ \\
Total problems & 25.00 & 78.95 & $<0.001$ \\
\hline
\end{tabular}

On the DSM-oriented scales, generated by the $\mathrm{CBCL}$, the Internet Addicts group also showed a statistically significant correlation with Conduct Problems, Oppositional Defiant Behavior, Attention-deficit/hyperactivity Problems, Anxiety Problems and Affective Problems. The same correlation was not observed in the item Somatic Problems (Table 3).

Table 3. Comparisons between the Internet Addiction group and the non-addicted group versus the DSM-Oriented Scales from $\mathrm{CBCL}$

\begin{tabular}{lllc}
\hline & IAT $<50(\%)$ & IAT $\geq 50(\%)$ & $p$ \\
\hline Behaviorial problems & 6.94 & 36.84 & $<0.05$ \\
Oppositional defiant problems & 5.56 & 26.32 & $<0.05$ \\
Attention-deficit/hyperactivity problems & 16.67 & 57.89 & $<0.001$ \\
Somatic problems & 14.08 & 31.58 & $>0.05$ \\
Anxiety problems & 11.11 & 47.37 & $<0.05$ \\
Affective problems & 18.06 & 36.16 & $<0.001$ \\
\hline
\end{tabular}

\section{DISCUSSION}

This study researched the prevalence of internet addiction and the correlated behavioral symptoms and functional impairments among 12 to 16-year-old students of public and private schools in Curitiba, Paraná. This is the first Brazilian survey to address this issue within the adolescent population.

According to the study, the prevalence of internet addiction in this population was $21 \%$. This is consistent with the results of international studies ${ }^{18,22,28}$. However, as the definition of internet addiction is still controversial in literature, we can find several ways to measure and classify this behavior, since there is no standardization or consensus on the issue to date. Additionally, the cut-off points of the IAT have been validated from studies in the adult population, and it is not sure to what extent these values can be extrapolated for use in the adolescent population. Regarding internet addiction, there were no differences between the private and public school results. This could be partly explained by the growing popularity of mobile devices and internet access.

It is also worth noting the low parental consent for participating in the study. Only 151 of those 500 questionnaires initially distributed were returned. It is not possible to know if those who agreed with the study had already noted problems regarding the use of Internet by their children, creating a selection bias.

In the Internet Addicts group, a statistically significant correlation with Withdrawn/Depression, Anxiety/Depression, Social Problems, Thought Problems, Attention Problems, Rule-breaking and Aggressive behavioral symptoms was observed, in accordance with international data. However, being a cross-sectional study, it was not possible to establish causality links between internet addiction and psychopathological symptoms. We can not establish whether individuals who already have these behavioral symptoms can also develop an internet addiction or if the internet addiction would lead to the emergence of these symptoms. To define this relationship, prospective studies involving clinical follow-up of these adolescents are needed.

One of the main objectives of this study is to raise awareness and generate interest, particularly among pediatrician doctors, regarding the growing use of the internet by children and adolescents, as indicated by IBGE data, and its correlation with behavioral symptoms and functional impairments, suggested by this study. It is essential that questions relating to the Internet use are raised in the anamnesis of the adolescent population, since an internet addiction diagnosis may be linked to neurobehavioral symptoms.

The prevalence of internet addiction among adolescents is significant, with no differences concerning the attended school system, within the population studied. There is a correlation between internet addiction and behavioral symptoms such as Withdrawn/Depression, Anxiety/ Depression, Social Problems, Thought Problems, Attention Problems, Rule-breaking and Aggressive Behavior, as well as impairment in extracurricular activities, academic performance and social relationships (Total Social Competence). Both Internalizing Problems and Externalizing Problems are more frequent in the Internet-addicted population. It is important that the question about the use of Internet becomes a routine in pediatric consultations, in order to identify children and adolescents at risk for both internet addiction and for behavioral symptoms.

The study's limitations are, as follows, (a) this is a crosssectional study and therefore it cannot establish a causal 
relationship between the internet addiction and the behavioral symptoms; (b) the total sample and the response rate were low, which may cause a selection bias, since the individuals who agreed to participate in the study may already have problems concerning the use of Internet or mental and behavioral symptoms; (c) two questionnaires, the IAT and the CBCL, were used in this study, and the response bias must be considered; and finally (d) internet addiction is not included in the DSM-V or the International Classification of Disease - 10 (ICD-10), meaning there's no definitive diagnostic criteria. Despite these limitations, the present study shows that internet addiction is prevalent among Brazilian adolescents and it seems correlated with behavioral symptoms and functional impairment. Future research is necessary to corroborate our results.

\section{INDIVIDUAL CONTRIBUTIONS}

Mayara de Rezende Machado - Worked to produce the article through concept, planning, data acquisition, analysis, writing and revised the manuscript.

Isac Bruck - Worked with data interpretation, critical review and approval of the final version of the article (revised).

Sérgio Antonio Antoniuk - Has worked in data interpretation, critical review and approval of the final version of the article (revised).

Mônica Nunes Lima Cat - Has worked in data interpretation, critical review and approval of the final version of the article (revised).

Maurício César Soares - Has worked in planning and data acquisition.

Alcir Francisco da Silva - Worked to produce the article's concept, planning, data interpretation, critical review and approval of the final revised version.

\section{DISCLOSURE STATEMENT}

No conflicts of interests are present among the authors of this paper.

\section{ACKNOWLEDGMENTS}

The authors wish to thank the family members for contributing to this study.

\section{REFERENCES}

1. IBGE. Pesquisa Nacional por Amostra de Domicílios - Acesso à Internet e Posse de Telefone Móvel Celular para Uso Pessoal 2011. Rio de Janeiro; 2013.

2. TIC Kids Online Brasil - 2016 Crianças e adolescentes. Available at: http://cetic.br/pesquisa/kids-online/indicadores. Accessed: 06/01/2015.
3. Valkenburg PM, Peter J. Online communication among adolescents: an integrated model of its attraction, opportunities, and risks. J Adolesc Health. 2011;48(2):121-7.

4. Arab E, Díaz A. Impacto de las redes sociales e internet en la Adolescencia Aspectos positivos y negativos. Rev Méd Clín Las Condes. 2015;26(1):7-13.

5. Fioravanti $G$, Dèttore $D$, Casale $S$. Adolescent internet addiction: testing the association between self-esteem, the perception of Internet attributes, and preference for online social interactions. Cyberpsychol Behav Soc Netw. 2012;15(6):318-23.

6. Morahan-Martin J, Schumacher P. Loneliness and social uses of the Internet. Comput Hum Behav. 2003;19(6):659-71.

7. Eisenstein E, Estefenon SB. Geração digital: riscos das novas tecnologias para crianças e adolescentes. Rev HUPE. 2011;10(Supl 2):42-52.

8. Young KS. Internet addiction: the emergence of a new clinical disorder. CyberPsychol Behav. 1998;1(3):237-44.

9. Young KS, Abreu CN. Dependência de internet: manual e guia de avaliação e tratamento. Porto Alegre: Artmed; 2011.

10. Abreu CN, Karam RG, Góes DS, Spritzer DT. Dependência de Internet e de jogos eletrônicos: uma revisão. Rev Bras Psiquiatr. 2008;30(2):156-67.

11. Yu JJ, Kim H, Hay I. Understanding adolescents' problematic Internet use from a social/ cognitive and addiction research framework. Comput Hum Behav. 2003;29(6):2682-9.

12. Zhou Y, Lin FC, Du YS, Qin LD, Zhao ZM, Xu JR, et al. Gray matter abnormalities in Internet addiction: a voxel-based morphometry study. Eur J Radiol. 2011;79(1):92-5.

13. Brezing C, Derevensky JL, Potenza MN. Non-substance-addictive behaviors in youth: pathological gambling and problematic Internet use. Child Adolesc Psychiatr Clin N Am. 2010;19(3):625-41.

14. Weinstein A, Lejoyeux M. Internet addiction or excessive internet use. Am J Drug Alcohol Abuse. 2010;36(5):277-83.

15. Young KS. Caught in the net: how to recognize the signs of internet addiction - and a winning strategy for recovery. New York: John Wiley \& Sons; 1998.

16. Conti MA, Jardim AP, Hearst N, Cordás TA, Tavares H, Abreu CN. Avaliação da equivalência semântica e consistência interna de uma versão em português do Internet Addiction Test (IAT). Rev Psiquiatr Clin. 2012;39(3):106-10.

17. Moreno MA, Jelenchick L, Cox E, Young H, Christakis DA. Problematic internet use among US youth: a systematic review. Arch Pediatr Adolesc Med. 2011;165(9):797-805.

18. Kaess M, Durkee T, Brunner R, Carli V, Parzer P, Wasserman C, et al. Pathological Internet use among European adolescents: psychopathology and self-destructive behaviours. Eur Child Adolesc Psychiatry. 2014;23(11):1093-102.

19. Lam LT, Peng Z, Mai J, Jing J. The association between internet addiction and self-injurious behaviour among adolescents. Inj Prev. 2009;15(6):403-8.

20. Puerta-Cortés DX, Carbonell X. Uso problemático de Internet en una muestra de estudiantes universitarios colombianos. Avances en Psicología Latinoamericana. 2013;31(3):620-31.

21. Banjanin N, Banjanin N, Dimitrijevic I, Pantic I. Relationship between internet use and depression: Focus on physiological mood oscillations, social networking and online addictive behavior. Comput Hum Behav. 2015;43:308-12.

22. Yoo HJ, Cho SC, Ha J, Yune SK, Kim SJ, Hwang J, et al. Attention deficit hyperactivity symptoms and internet addiction. Psychiatry Clin Neurosci. 2004;58(5):487-94.

23. Yen JY, Ko CH, Yen CF, Wu HY, Yang MJ. The comorbid psychiatric symptoms of Internet addiction: attention deficit and hyperactivity disorder (ADHD), depression, social phobia, and hostility. J Adolesc Health. 2007;41(1):93-8.

24. $\mathrm{K}_{0} \mathrm{CH}$, Yen JY, Yen CF, Chen CS, Chen CC. The association between Internet addiction and psychiatric disorder: a review of the literature. Eur Psychiatry. 2012;27(1):1-8.

25. Achenbach TM. Manual for the Child Behavior Checklist/6-18 and 2001 profile. Burlington: University of Vermont; 2001.

26. Bellina M, Brambilla P, Garzitto M, Negri GA, Molteni M, Nobile M. The ability of CBCL DSM-oriented scales to predict DSM-IV diagnoses in a referred sample of children and adolescents. Eur Child Adolesc Psychiatry. 2013;22(4):235-46.

27. Bordin IAS, Mari JJ, Caeiro MF. Validação da versão brasileira do "Child Behavior Checklist" (CBCL) (Inventário de Comportamentos da Infância e Adolescência): dados preliminares. Rev ABPAPAL. 1995;17(2):55-66.

28. Kormas G, Critselis E, Janikian M, Kafetzis D, Tsitsika A. Risk factors and psychosocial characteristics of potential problematic and problematic internet use among adolescents: a cross-sectional study. BMC Public Health. 2011;11:595. 